\title{
Herrn Professor Hans Fischer zum 80. Geburtstag
}

Das letzte Heft unserer Zeitschrift Gesnerus, das im Jahr 1972 die Drukkerei verläßt, soll nicht in die Welt hinausgehen, ohne daß wir ihrem hochverehrten Redaktor, Hans Fischer, herzliche Glückwünsche zum 15. Dezember entbieten. Seit dreißig Jahren versieht Professor Fischer das Amt des Redaktors, wahrlich Grund genug, um ihm auch jetzt wieder zu danken für alle die viele Arbeit, die er im Nebenamt auf sich genommen hat.

Darüber hinaus darf aber unser Zürcher Kollege auch einmal als der Mann «hinter den Kulissen» gewürdigt werden, dem in maßgebender Weise die Etablierung der Medizingeschichte an der Universität Zürich zu verdanken ist. Nachdem durch den kunstliebenden Praktiker PD Dr. Gustav Wehrli der Grundstock eines medizingeschichtlichen Museums geschaffen worden war, galt es, diese Sammlung durch die Schaffung einer Professur aufzuwerten. Dies geschah im Jahre 1951 durch die Ernennung des Internisten Bernhard Milt zum Extraordinarius. Der ganze Aufbau wurde fünf Jahre später, nach dem Tode Milts, gekrönt durch die Berufung von Erwin H.Ackerknecht und die Schaffung des ersten Lehrstuhls für Geschichte der Medizin in der Schweiz. Alle diese Etappen hätten ohne die zielbewußte Förderung durch Hans Fischer im Schoße der Medizinischen Fakultät nicht zurückgelegt werden können, wofür ihm heute an dieser Stelle gedankt werden soll, auch wenn es gegen den Willen des überaus bescheidenen Gelehrten geschehen mag.

Als Rektor der Universität Zürich im Jahre 1956 hielt der Pharmakologe Hans Fischer seine Festrede über «Das Menschenbild im Lichte der Heilkunde», die den Untertitel «ein Beitrag zu einer ärztlichen Anthropologie» trägt. Mit diesem abschließenden Hinweis soll zum Ausdruck gebracht werden, worum es dem Humanisten Hans Fischer in seinem ganzen Wirken, sowohl als Medizinhistoriker wie als Pharmakologe, geht: nämlich um die Bewahrung eines weltanschaulich getragenen Bildes vom Mitmenschen, von dem sich der Arzt leiten lassen soll, ganz im Sinne des Satzes am Schluß der genannten Rede: «Hüten wir uns als Ärzte, neben der naturwissenschaftlichen Kausalität die ethische Aufgabe, welche dem Verantwortungsbewußtsein und damit der menschlichen Freiheit entspringt, zu vernachlässigen oder geringzuachten.»

Heinrich Buess 